\title{
THE IMPACT OF ACCESS TO POST-SECONDARY EDUCATION \\ INFORMATION ON "RURAL ORIGIN" STUDENTS' ACCESS TO \\ HIGHER EDUCATION: A CASE OF THREE SCHOOLS IN \\ NTABAMHLOPHE, KWAZULU-NATAL
}

\author{
M. B. Njoko \\ Turfloop Graduate School of Leadership \\ University of Limpopo \\ Sovenga, South Africa \\ e-mail: mnqobi.njoko@ul.ac.za
}

\section{ABSTRACT}

Inequalities in recruitment, enrolment and throughput rates in higher education among different socio-economic classes in the democratic South Africa have remained challenging to reduce. Unpacking spatial differences in access to post-secondary education information can strengthen initiatives aimed at reducing such inequalities. Research on access to and success at postsecondary education has based the vulnerability of students from disadvantaged backgrounds heavily on financial constraints. Neglecting the issue of information or Higher Education knowledge which plays a very important role in decision making. It is a challenge for people from disadvantaged backgrounds to find their way through the inexplicable labyrinth of academic forms, financial aid applications, faculty handbooks and prospectuses. Even in Higher Education people have access to formal and informal resources of information. The formal resources which include guidance counsellors, college training in Advanced Placement (AP) courses (in the case of USA), college handbooks and university open days are readily available at wealthier schools than the poorer ones. It is however the informal knowledge networks that really matter in preparing for Higher Education application and admission. This article argues that the lack of exposure to useable post-secondary education information in rural based prospective students results in uninformed and underprepared learners about prospects and possibilities of educational options and opportunities. Hence later on they take longer to complete or even drop out.

Keywords: post-secondary education information, access, higher education enrolment, socioeconomic inequality

\section{INTRODUCTION}

Inequalities in enrolment and graduation rates in Higher Education ${ }^{1}(\mathrm{HE})$ among different societal classes in the democratic South Africa have remained challenging to reduce. Though South Africa has a fast growing black, middle-upper class population, the rural populations remain socio-economically disadvantaged through marginalisation. Over the last five decades, 
enrolment systems in tertiary education globally have seen huge changes and rapid expansion to accommodate greater numbers of students. This benefit, however, has not been shared equally by all socio-economic groups (Council on Higher Education (CHE) 2010; Ziderman 2009, 227; Herman 1995).

Students from socio-economically disadvantaged backgrounds end up educationally disadvantaged in terms of accessing HE. Herman $(1995,262)$ has observed that inequalities in the distribution of schooling in developing countries remains a reality. In South Africa, poor communities, in particular those of rural Africans, live through the legacy of past inequalities. According to Ziderman (2009, 227), "the on-going thrust towards expanding university enrolment has left behind traditionally disadvantaged groups such as low income families, ethnic minorities and rural populations". There have been significant achievements, especially in opening Higher Education for greater participation by all citizens regardless of race, gender, economic class or religion. Statistics indicate that from 1994 to 2015, the total enrolment has increased by over 100 per cent (CHE 2010). However, demographics show that African students, specifically those from socio-economic disadvantaged backgrounds, remain underrepresented in enrolment rates (Scull and Cuthill 2010; CHE 2010; Ziderman 2009; Herman 1995).

According to the Organisation for Economic Co-operation and Development (OECD 2012, 102), chances that a 20-34 year-old will attend HE are low if his or her parents have not completed upper secondary education (which is often the case in rural areas). Furthermore, "On average across OECD countries, a young person with at least one parent who has attained a tertiary degree is almost twice as likely (odds of 1.9) to be in higher education”. Therefore, this study is significant in understanding spatial inequalities' (rural vs urban) impact of access to information in accessing Higher Education and can also strengthen initiatives aimed at closing this gap.

\section{PROBLEM STATEMENT}

It is important that we understand the impact information has on preparing a prospective student for Higher Education. Urban population generally has easier and faster access to information compared to their rural counterparts. Therefore, access to information is arguably a challenge specific to rural schools because their urban counterparts are, by virtue, already advantaged in this regard. Moreover, urban population is more educated; therefore, learners in urban areas have people who can give them career guidance. The article aims to address the impact this has on post-secondary education access for rural based learners who want to study further. 


\section{STUDY AREA}

Census 2011 (2011, 39-41) revealed that only 1.6 per cent of Africans in South Africa had completed a Bachelor degree and only 2.2 per cent in KwaZulu-Natal (KZN). KZN is an interesting choice because it is the second most populated province with over 10 million people; however, its HE attainment levels are very low in comparison to other provinces. The argument Vally (2007, 17) makes is that the current international trends in HE that encourage individualism and competitiveness, managerialism, marketization are some of the factors that contribute to universities' disincentive to enrol students from poor backgrounds. This could result in the segregation among the previously disadvantaged groups. The socio-economically disadvantaged rural students could be left behind when compared to their counterparts in cities and/or urban areas. Census $2011(2011,45)$ reported that in KZN, 3.4 per cent of urban dwellers had completed a Bachelor degree as compared to 0.8 per cent of rural dwellers.

What further complicates matters in KwaZulu-Natal (KZN) specifically is that prospective students can no longer apply directly to each of the public Universities, Universities of Technology and some Colleges in KZN. KZN is the only province with a Central Applications Office (CAO) which all Universities and Universities of Technology and some FET colleges in KZN (only) use to administer new applications. CAO processes applications for first time admission to partner institutions in KZN. It is a prospective student's responsibility to get the CAO application form which is available at all HEIs, libraries and some public institutions. According to the CAO website (http://www.cao.ac.za/, accessed 1 June 2015), the application fee (non-refundable) is R200 if form and fee reaches the CAO before 31 October and R400 on or after 01 November. They also make it clear that "If [they] do not receive payment, your application information will not be made available to the institution/s". The CAO had a road show to distribute the application forms; however, in their posters, as can be seen on the website, they only visited shopping malls in Durban and nearby township of Umlazi, KZN.

\section{ACCESS TO HIGHER EDUCATION}

There are several challenges hindering students particularly in the African continent to fully access HE; some are collective and some are specific for certain groups. According to Altbach, Reisberg, and Rumbley (2009, 38), Sub-Saharan Africa has the lowest enrolments in the world as only 5 per cent of the age cohort is enrolled in HE. Teffera and Altbach $(2004,21)$ stated that there are common elements and definitely common challenges such as funding, resource scarcity, gender imbalance, language barrier and growing youth population, but it is difficult to generalise about a continent as large and diverse as Africa. Johnstone $(2004,12)$ noted that the demand for tertiary education has reached levels never before imagined for Sub-Saharan Africa. 
This demand is from students themselves, their families and the governments. This is because of "the occupational and social status and greater earnings it is presumed to convey" and from the governments' side, it is for the social, cultural, political, economic benefits it is presumed to bring (Johnstone 2004, 13).

The broader challenges are mostly general in accessing HE in the Sub-Saharan African region when coming from a disadvantaged background. This article limits itself to one issue and which is arguably an understated one; access to sufficient, usable post-secondary education information. Altbach et al. $(2009,40)$ state that " [g] eography is easily underestimated as a factor that contributes to unequal participation in higher education". According to Atuahene and Owusu-Ansah (2013, 07), access and participation in HE is highly determined by the geographical location or region of the high school one attends. Rural populations in general are more distant from HEIs than their urban counterparts, and this adds to the challenge of improving access for this group (Atuahene and Owusu-Ansah 2013; Altbach et al. 2009). In theory, technology should close this gap; however, Altbach et al. $(2009,40)$ states that rural population is less likely to have the necessary means to access it.

The differences in access to post-secondary education information between rural and urban and also between different socio-economic groups lead one to question how this information is communicated. Communication or recruitment methods of prospective students employed affect and determine who gets information.

\section{THE “GAP” BETWEEN HEIS AND PROSPECTIVE RURAL STUDENTS}

South Africa has a large rural population, that is, 36 of total population as of 2014 World Bank data (http://wdi.worldbank.org/table/3.1, accessed 10 December 2015). Therefore, it is important that we understand the challenges specific to rural schools and communities in accessing higher education. Dissemination of sufficient, useable information to rural and other disadvantaged schools, even in townships and urban areas, can have a positive impact on learners, and their families benefit from equity reforms and government financial assistance like National Student Financial Aid Scheme (NSAFS) which is the largest funder of HE in South Africa. The challenge of universities not reaching these learners has been identified and HESA, through their initiative National Information Service for Higher Education known as "NiSHE", are trying to deal with it. The NiSHE Project has been in operation since 2003. It was originally conceived against the background of the national policy imperatives of increasing and broadening student access into Higher Education. According to the HESA (2014, 33) report, the NiSHE initiative so far has focused on providing information and guidance to prospective students on application procedures and various courses offered by HEIs. 
NiSHE contains admission criterion for institutions, fees, different study areas, possible financial aid, loans, bursaries, grants, to mention some. HESA (2011) asserts that high school learners could use this information to make wise choices about their careers and future. HESA has published on their website (www.universitiessa.ac.za, accessed June 2015) that it is estimated that the NiSHE advertorials have been seen and read by well over 500000 youth (1624 year olds) and radio campaigns reached more than four (04) million listeners for a period of 3 months in 2011. To further disseminate information to the learners, an online system is also available. This is more than university marketing and recruiting campaigns reach, and it is important to note that rural areas still rely largely on radio, but universities in South Africa hardly advertise on or use radio as a platform to share information.

A case study profile conducted by McMillan and Barrie (2012) found that in the 2008 cohort of dentistry students at one of the 23 [at the time] universities, only 7 per cent $(n=22)$ of the cohort $(n=304)$ were from rural areas. With regards to sources of information, the results show that rural students relied on assistance from those with university experience to apply and register for course information and funding opportunities McMillan and Barrie $(2012,08)$. However, they lacked immediate access to people with insight into the academic and sociocultural aspects of higher education.

\section{RESEARCH QUESTIONS AND RESEARCH OBJECTIVES}

With the above background in mind for this article, the following research objectives were adopted:

- Determine whether the learners in rural schools and communities have access to sufficient post-secondary education information to make informed HE decisions.

- Identify the sources of post-secondary education information learners of rural schools relied on.

The broad question the research attempts to contribute to, is: What are the experiences of prospective students of rural origin with accessing HE information they need to apply for studies?

\section{RESEARCH DESIGN AND METHODOLOGY}

The study employed qualitative methods of enquiry. As mentioned in the research question, the study sought to investigate the lived experiences with information or lack thereof in trying to access HE from a rural school or community. The study was more interested in the learners' 
experience during their HE application process, what challenges they encountered and how each one of them dealt with these and what each learner perceives as sufficient information. The study employed case study research or methodology.

\section{Participants}

Due to study length restrictions and other limitations such as time and resources, our sample was only drawn from three (03) high schools from Mbabazane Local Municipality, located in Zwelisha, Mhubheni and Shayamoya locations. Twenty (20) Grade 12 learners availed themselves to be interviewed. The schools combined had 112 grade 12 learners in total, made up of 48 females and 54 males. The sample was closely divided between the schools and had twelve (12) males and eight (08) females. Three teachers and one School Liaison Officer (SLO) from [University A] were selected following purposive sampling. Purposive sampling allows the researcher to draw a sample from which the most information can be learned and allows the researcher to create a sample which is representative of the population (Marks and Yadley 2004). One of the teachers was a Grade 12 Life Orientation teacher as career guidance is part of the syllabus and the other two were class teachers. The reason to interview teachers is that it is assumed they will be the most involved in their learners' HE application process and career guidance. Therefore, they are expected to have the most information regarding application processes, what information their learners need mostly and what challenges they face with the learners in trying to access information. The Central Applications Office (CAO) was requested to participate as a key stakeholder; however, they declined.

\section{Data collection and analysis}

Semi-structured individual interviews with a different interview guide for each group, ranging from sixty (60) to ninety (90) minutes were used as a data collection method for all groups of participants. At the schools, interviews were held in any available classroom for both learners and teachers, and the SLOs interview was held at the university in their office. Interview guides were used for all participants. The use of semi-structured interviews opens the possibility for participants to express themselves in ways that are less controlled and pre-determined by the researcher (Marks and Yardley 2004). The interviews' overall aim was to engage in a conversation regarding the perceived information about HEIs the learners have, their sources for this information, their ability to use the information on HEIs they receive to apply for study and what they think could be done to make HE information easily available to rural areas and schools. The information gathered should lead to a conclusion about the perceived availability or lack of sufficient information in these schools. 
The interviews were recorded on audio-tape and transcribed. The content obtained from the twenty (20) interviews was systematically coded and analysed using content analysis. According to Kumar (2005), content analysis entails coding of raw data into relevant categories or nodes. This method is commonly used to detect recurring patterns of meaning or themes across the sample. A qualitative data analysis software NVIVO11 was used for the data management and analysis.

\section{FINDINGS AND DISCUSSION}

The findings and discussion will be presented together for all groups of participants as that makes it easier to follow the conversation and to make linkages across.

\section{Theme 1: Sourcing the Information}

The move towards marketization in HE has left institutions heavily competing for the "best" students and funds; consequently, institutions are careful about how and who they recruit. For the learner participants, their sources of information are not as wide and vast as one would think they are in the age of technology and information. Six (06) of the learners had solely relied on the $\mathrm{CAO}$ handbook ${ }^{2}$ or brochure while four (04) of the learners had relied on the CAO handbook and someone with HE knowledge. Thando and Malema relied on the handbook and their siblings who are already at HEIs. Khangiwe, for her Dental Therapy application, relied on the handbook but also had assistance from her relative who is already working in the health industry and Nontuthuko used the handbook and her L.O. teacher for clarity. Three (03) of the learners said they had primarily relied on teachers at school, again mostly the L.O teachers with all the steps of their applications. Only three (03) of the learners said they had used internet or other media (TV, radio, newspapers) for information.

These findings are in line with those of the study by McMillan and Barrie (2012) which found that learners in rural areas have limited sources and mostly lacked immediate access to people with knowledge on HE. They are also in line with those of older studies like Martin (1996) conducted in one University in Australia with first year students on their sources of postsecondary information. The study found that 81 per cent relied on university admission guide, 50 per cent on the school, 48 per cent on other people with university knowledge and while only 8 per cent relied on family.

More than half of the learner participants expressed a general lack of understanding of the information contained in the CAO handbook. They felt that they only really understood the subject requirements part. The learner participants felt that the codes used for different study programmes, institutions, campuses, semester and level of study are confusing and not 
understandable. In general, four (04) felt they had a good understanding of what was required to correctly fill in the application form and submit it while nine (09) expressed frustration. Khangiwe said "No, information was not satisfactory. I would have liked to have more information. Like Civil engineering, I put it on my form but I don't really know what it is." Andile said he would like to study something sports related but on the handbook, the subjects required and where to study are not specified and that is confusing. Some of the learners still had questions about the basics such as subjects required and some wanted to know more about duration of the study, modules and majors. Therefore, on the question of how well they understood the information they had, the understanding was basic.

The teachers had a good understanding of the information contained in the application handbook and did some research on their own and used their previous experience to assist the learners. Even for the teachers, the application handbook is the main source of information. "I study the manual and rely on it mostly. The manual guides you on every step from step 1 to the last step. That's what I help them with, subject choices and posting the forms" said one of their class teachers. Mapholoba said as the L.O. teacher, he gets invited to workshops by the Department of Education and that is where they get more information and get to ask questions and share experience with colleagues.

In these schools, the teachers play a very important role in career decisions of the learners because most do not have anyone else with HE experience to get help from. Mrs Khumalo said "They applied as I kept on encouraging them, helping them fill in the forms, helping them select courses based on their subject packages. Explaining the courses to them though I do not know some of them but most have been successful."

How do they get hold of the application handbook and application form since the CAO makes it an individual applicant's responsibility to get it? The L.O teacher said the Department of Education sends a package via post mail with the handbooks and forms; however, there are usually only 10 in the package. Another way to get them is on these workshops or conferences the L.O. teachers attend. For the learners, twelve (12) of them received the application handbook and form at school, two (02) received it at a career exhibition which was only for the best performing learners in the region. Mbali said "we were given the opportunity to go on a camp, we got the handbooks early and they were only seven from here and that's why I applied early". Swakhile did an online application using his smart phone. The learner participants said if the forms were not being handed out at school or the school was not getting them on their behalf, they would not have applied as they do not know where and how to get them.

Career exhibitions and university open days are some of the platforms used by HEIs to give information to prospective students. These can be very informative and beneficial as you 
have more than one HEI and possible funders and employers at career exhibitions; at university open days, you get to talk to all departments you are interested in and discover new ones. However, are these accessible to every prospective student? Eleven (11) of the learners mentioned that they have attended a career exhibition held in Ladysmith. According to google maps Estcourt, the local towns the two schools fall under is approximately 90 kilometres from Ladysmith. The learners said this meant they needed money for transportation to get there, and getting this money was another challenge. For the eleven that managed to attend, they complained that it was "too crowded", mostly colleges were there, and focus was on giving them study tips and signing registers for having attended.

There were two different types of career exhibitions, the one in Ladysmith was for the whole Ukhahlamba Region and every school and learner was welcome. The second one I have termed "exclusive" because it was only by invitation and only the top 7 performing learners were invited. It was also held at a private boarding school. The two leaners in the sample who had been part of the chosen to go on the exclusive career exhibition had a different experience though. They were given packages with all the information they need and therefore could apply earlier than their classmates and understood very well what they were applying for, where and how to prioritise choices in the application. Mxolisi and Mbali shared the same sentiments about their experience. They got all their questions answered, they did not have to pay to go and it was a valuable experience. This method of student recruitment (inviting seven "best" in each school) confirms the statement made by Wiese, Van Heerden and Jordaan $(2010,151)$ that with the changing landscape in South African HE and changes in funding structure, institutions are becoming more market oriented and that has placed greater emphasis on throughput. This emphasizes the vital importance for institutions to recruit high-achieving students who are likely to graduate in minimum time.

The learners stated that they do receive some information on different aspects of the application and enrolment process but they do not know what to do with that information. For example, with applications, they know they need a CAO application form but do not know where to get the forms and cannot afford to travel to where they cannot get them. Similarly, with different types of bursaries, scholarships and particularly NSFAS, they only know the names but they are not informed about how to access them, who they fund (target group) and what they cover. They bring their questions to their schools which as the teachers expressed, also has limited information and no resources like a computer to access information.

As stated in the previous section, academic achievement is even lower among the rural population in KwaZulu-Natal; only 0.8 per cent of KZN rural population has a HE qualification (Census 2011 2011). This spatial inequality in education achievement will continue if learners 
in rural schools like in this study continue to be deprived of post-secondary education information. According to the United Nations Development Programme (UNDP 2014, 35) location is a crucial determinant of access to opportunity and rural areas, informal settlements, townships in South Africa "are at a distinct disadvantage". Such inequalities are the legacy of apartheid separation which took a spatial form. According to the UNDP $(2014,36)$, the role of spatial inequality is so relevant to the South African story that it is important that we give attention to its continued role in reproducing other forms of inequality. "It has a distinct rural and urban characteristic" UNDP $(2014,36)$. Overall, inequality in opportunity and education have a significant spatial dimension.

\section{Theme 2: Key institutional role players}

As it was discussed in the previous section that KZN is a special case because HEIs have an independent body, the CAO that handles applications. The learners were asked about both the CAO and HEIs. The study found that neither the CAO nor any HEI (not just those with campuses in KZN) has made any visits to these schools in their recruitment for the 2016 academic year. For these learners, the only interaction with people who are well informed about the application process, careers, funding opportunities and other specifics was at the regional career exhibition in Ladysmith which those who could afford to attend, find it to have not been beneficial because of the crowds and what its focus was on.

The study found that the learners do know that the CAO is just a body that administers applications but does not do any selection for study programmes for any institution. However, they do not know where the CAO is located or how they could contact them. Moreover, they do not know or understand the difference between a University and a University of Technology. This is important information to know and understand when applying to increase your chances of being accepted, to understand what your grades qualify you for, the costs and which institution has campuses where. To get an institutional perspective on the process of student recruitment, the CAO and SLOs were contacted for interviews.

One category of the people who represent an institution and are key in student recruitment and post-secondary education information dissemination are the School Liaison Officers (SLOs). One of the SLOs from [University A] gave an insight into their recruitment strategy or plans. The SLO explained that when they do school visits, they do in-depth presentation on what the subject packages allow the learner to study, and what career path a certain degree leads to. They also show them how to correctly complete the $\mathrm{CAO}$ form, access funding opportunities and in rural schools also give learners a "Study at [University A] book" which gives them an idea of what Campus $\mathrm{A}$ is about since they cannot visit the web-page. 
The SLO explains, "the book basically tells you what Campus A is about. It tells you where the campuses are, how to apply, so I've done a detailed step by step on how to apply to [Campus A], closing dates, just the important thing ... how we select students for our programmes using the APS calculation which I go into depth with them on how to understand selection procedure."

For [University A] they use the Data of Management Information (DMI) report to select which areas they will do exhibitions at or go to when invited. They then try to balance out the regions they will visit so that they do not only visit closest by distance and quintile 5 schools. SLO states, "I took the DMI report which gives you an understanding of the number of schools that feed into [University A] which is approximately 4500 from throughout the country. So what I did was I broke it down into the different regions that we will focus on."

Currently, 3300 schools feed into [University A]. SLO explains "So you take the total number the school has given in the past 6 years and rank it from highest to lowest then your top schools are those ranked in the top 100 and your quantile 1, 2 and 3 don't fall into that". This means that out of the 3300 schools, their priority are the high performing schools in the country and therefore they do not visit rural schools directly or individually because they fall into quantile 1-3 which cannot compete for the top 100 spots. For the cluster visits they do in rural schools, they use a report from the Department of Basic Education which gives them again, the top 100 performing schools in quantile $1-3$ and visit those.

It then made sense why these learners barely understood what they were applying for. The schools get "punished" if I may put it that way, first for not giving the institution the most number of students and secondly for not being in the top 100 as ranked by the Department. of Education. For the institution, this is a simple and straight forward recruitment strategy and they seem to ignore what effects it has on the socio-economically disadvantaged segments of society. Indeed, institutions are positioning themselves to attract the best student. What this does is also to perpetuate the spatial inequalities in HE because these top 100 schools the SLOs visit serve the middle-class and upper families.

Under the Theory of Strategic Information Transmission, Cai and Wang (2006) explain that for people to make good decisions, they rely on those with information, who may or may not withhold the information depending on how they assume the decision will affect them. Again, the recruitment strategy employed seems to be in line with the assumptions of the theory that the sender (HEIs in this case) will transmit less information to a certain receiver (prospective students) if giving more information will result in an action that is not favourable to the receiver. Recruiting and admitting in the rural areas or in the socio-economically disadvantaged population means the institution must provide for such students, and given the 
competition among institutions, no one wants to take that responsibility.

The SLO officer confirmed that there is a challenge with getting information to rural schools. The learners in this study pointed out the challenge of delayed CAO forms and only being introduced to career talks in Grade 12 when it is already too late. According to the SLO it is a common challenge in rural areas:

"The main challenge is that they get the CAO forms late, so if you looking at your Grade $12 \mathrm{~s}$, they don't get the forms on time. They say that the department posts it to them but they don't have post boxes and if sent to the school it's too late. The other challenge is that when you look at Grade 09 to 11 , they really excluded so the only time that you really get information is in Grade 12 which is why since last year we been doing from Grade 09."

From the sender's (HEI) side, there are also challenges they face when trying to reach rural areas and learners. At Campus A, there are only two SLOs for the whole institution with campuses in different cities. They do not get enough funds to do as much as they wish to reach learners. Rural schools are generally far apart, making it difficult to visit more than one school per day while they can visit three schools per day in quantile 4 and 5. The SLO also mentioned that the fact that rural schools do not have access to computers is a challenge for them as SLOs and a disadvantage to the schools because communication is difficult as they cannot send them a lot of information that they usually share with schools.

On the issue of cluster visits or exhibitions, the SLO explained that the reason they only invite only the top 10, for example, from each school is related to the issue of space. Rural and township schools normally have overcrowded classrooms and inviting the whole school in a cluster visit of maybe 10 schools would not work. Due to such challenges, they were only able to see 50 quantile 1 to 3 schools through cluster visits throughout KZN. The SLO also mentioned that they do not have any other means to give information to schools except exhibitions and visits because they cannot distribute via the CAO.

\section{Theme 3: Challenges in accessing the required information}

Some specifically relate to sourcing the information, some to the costs and some to understanding the information. Seven (07) of the learners mentioned that their biggest challenge has been getting the information and understanding it. They stated that they had to get information they needed themselves, try understand it and learn how to put it into good use. Moreover, the challenge is that they get introduced to HE discussions when already in Grade 12 when it is too late. Consequently, they end up filling in the form with choices of study they do not understand. 
Mncedisi said: "The most difficult here in rural areas is that we learn about most things once we already in grade 12, there's a lot we do not know about technology and universities. The only people who help us are teachers ... but what remains a challenge is getting the application forms."

Andile stated: "What gave me a real challenge is getting step by step information on how to go about with applying".

What is important to note is that the application form comes with the application handbook and prospectus. For these learners in rural schools, the handbook is what they rely on for all the information they need. If there are delays in getting these to them, then they have no other options to apply to HEIs in KZN. Not getting application forms and handbooks on time only delays but does not stop them from applying, and the challenge of relying on the post mail does not end there. During the time of the interviews, the teachers revealed that some of their learners had just missed their dates for selection interviews and entry tests at different institutions. How did this happen? They reply through the post mail, which is unreliable. Institutions had posted letters inviting the learners for interviews and entrance tests, but the letters arrived 2 weeks after those dates. One of the teachers revealed that seven of their learners had suffered from this misfortune. The only other way institutions communicate is via email, but learners do not have email addresses and also cannot access the CAO's online check system as often as they should.

Khangiwe explains: "It is difficult because we do not know and need someone to explain to us and we do not have them. So, when using the CAO handbook there is no one to clarify for you."

Swakhile also shared the same view as his peer: "There is only a few people that are educated and there is not anyone at all who has done what I want to study so there's no one to ask".

The challenge of understanding the information at hand or knowing what information you need is complicated by the fact that teachers in these schools also cannot help much. They are not equipped with resources, skills or knowledge to access the information their learners need. Mrs Khumalo stated: "It's difficult because even I do not know how to help them. I always tell them about NSFAS and Fundza Lushaka because that is all I know too ... but other than that, I also have no knowledge of how they can be assisted."

Another challenge is that of costs which was also mentioned with regards to travelling for career exhibitions, and learners have a challenge with costs to travel to town to access internet cafes. Lack of people in the area to take along their questions and also that teachers also saying they have limited information, learners must go search on the internet. The transport fare and the fee they must pay to use the internet is unaffordable so they can only go occasionally. These 
learners do not have the privilege of taking a taxi and go to the library to get application forms and handbooks like in urban areas where libraries get these delivered to them by the CAO and HEIs. The option of them going physically to the CAO or HEI to collect these early in the year is not even feasible because they would not know where to go and additionally, they would not afford transport fare to Durban or Pietermaritzburg, for instance.

Zamani explains: "We don't have computers here at school so we have to take a taxi and go to internet cafes in town; for 30 minutes, you pay R25 and it is not easy to go often because parents don't have that money".

These again speak to the spatial inequalities in South Africa because in urban areas, for most, the transport and internet café costs are not that high and some have internet access from home. Even if they did not have easier, cheaper internet access or the costs for transport were not low, their parents will have better paying jobs and therefore can afford it compared to these learners from families that are dependent heavily on government grants. According to Sikhakhane and Lubbe (2005) in urban areas, people have easier access to resources that can be used to access information. They further state that the internet has become the main source of information; however, rural populations in Africa, besides not having resources, also do not have the skills to navigate it.

The CAO imposes an application fee of R200 or R400 depending on when your application is received. This fee was identified as one of the reasons some do not apply or take long to have their applications posted. The application fee is unaffordable for most and their families. Their families have to take from the already limited grants and other sources of income to pay this fee. Though the learners agree that they cannot afford this fee, there was, however, a mixed reaction on whether they think it is necessary. Three (03) of the learners had to get part time jobs on weekends just to get the fee, but they also still believe it is necessary.

Mxolisi stated: "I can say that it is ok because of the process involved in application. But like me ... I got the CAO form in May but only sent it in September because I didn't have that money".

Lindokuhle stated: "It stops some learners from applying; if you do not have anyone at home, you can't have the money".

Sikhakhane and Lubbe (2005) argue that in poor, rural families, there is always a need to decide between putting food on the table and investing on educational resources and other costs not relating to the household. Because of the desire to go to university these learners and their families chose to make sacrifices and pay the application fee. If you are in a "no fee paying" school like these learners, shouldn't this application fee be waivered? This should to an extent increase the number of rural based learners who see $\mathrm{HE}$ as reachable and would be encouraged 
to then seek the information they need since that would be one challenge out of their way.

\section{CONCLUSION}

Indeed, the Higher Education sector in South Africa has had significant and commendable achievements which we cannot downplay. However, it is not yet representative of the South African diverse population, as it still serves mostly those who can afford. If the poor, socioeconomically disadvantaged and rural population are to benefit from the "massification" "democratisation" of HE, affirmative action enrolment policies, funding opportunities, access programmes and other strategies aimed at redressing past inequalities, they need to know about them. Marketization of HE has become a globally accepted phenomenon and HEIs' competition among themselves has had unforeseen consequences in student recruitment.

The study found that all twenty (20) of the learners had very limited sources of information with the CAO's application handbook being identified as the main source. Their teachers also relied on the handbook and because of lack of IT infrastructure or resources in rural schools, the handbooks are also the only source of information the SLOs can send to rural schools in general. Though sources of information were limited, the findings reveal that the understanding of the information received was also limited. This is based on the differences between what the learners want to study, the careers they want to go into and what they said they have applied for. This is a bigger challenge than actually not having access to the sources of information as it is directly linked to lack of career guidance and people with higher education knowledge in the community at large. This of course then later on affects the success in first year once these learners reach HEIs. Admission officers, orientation programmes and mentors need to acknowledge this lack of basic knowledge and understanding of what students of rural origin register for so that there could be systems in place to support them, specifically.

In conclusion, given that prospective students and their families make HE decisions based on the information they have and how they understand it, rural learners are disadvantaged. Furthermore, the methods employed by HEIs in recruiting prospective students result in the neglect of rural learners. It is recommended that the aspect of access to information or lack thereof be investigated and included as one of the barriers to HE for rural populations. This could see this aspect being given the necessary attention especially given that the Department of Higher Education is in the process of establishing a National Central Applications Office. A number of lessons can be drawn from the KZN CAO in terms of learners' access to and interaction with post-secondary education information and further, in relation to institutions reaching rural based prospective students. 


\section{NOTES}

1. Higher Education and Tertiary Education will be used interchangeably throughout this article and limited to Universities and Universities of Technology.

2. From here onwards, handbook refers specifically to the $\mathrm{CAO}$ applicant handbook unless otherwise stated.

\section{REFERENCES}

Altbach, P. G., L. Reisberg and L. E. Rumbley. 2009. Trends in global higher education: Tracking an academic revolution. Paris: UNESCO.

Atuahene, F. and A. Owusu-Ansah. 2013. A descriptive assessment of higher education access, participation, equity, and disparity in Ghana. SAGE Open 3(3).

Cai, H. and J. T. Wang. 2006. Over-communication in strategic information transmission games. Games and Economic Behavior 56(1): 7-36.

Census 2011. 2011. A profile of education enrolment, attainment and progression in South Africa. Pretoria: Statistics South Africa.

Council on Higher Education. 2010. Access and throughput in South African higher education: Three case studies. Higher Education Monitor 9. Pretoria: Council on Higher Education.

Herman, H. D. 1995. School-leaving examinations, Selection and equity in higher education in South Africa. Comparative Education 31(2): 261-274.

HESA see Higher Education South Africa.

Higher Education South Africa. 2011. Insight Issue 3, September, 2011.

Higher Education South Africa. 2014. South African higher education in the 20th year of democracy: Context, achievements and key challenges. Cape Town: HESA.

Johnstone, D. B. 2004. Higher education finance and accessibility: Tuition fees and student loans in Sub-Saharan Africa. JHEA/RESA 2(2): 11-36.

Kumar, R. 2005. Research methodology: A step-by-step guide for beginners. London: Sage Publications.

Marks, D. and L. Yardley. 2004. Research methods for clinical and health psychology. London: Sage Publications.

Martin, C. 1996. Institutional research and student recruitment or how do institutions of higher education know what attracts students to their doors? Market research can help. Australasian Association for Institutional Research 5(02).

McMillan, W. J. and R. B. Barrie. 2012. Recruiting and retaining rural students: Evidence from a Faculty of Dentistry in South Africa. The International Electronic Journal of Rural and Remote Health Research and Education Practice and Policy 12(1855). http://www.rrh.org.au (Accessed 2 June 2015).

OECD see Organisation for Economic Cooperation and Development.

Organisation for Economic Cooperation and Development. 2012. Education at a glance 2012: OECD Indicators. OECD Publishing

Scull, S. and M. Cuthill. 2010. Engaged outreach: Using community engagement to facilitate access to higher education for people from low socio-economic backgrounds. Higher Education Research \& Development 29(1): 59-74.

Sikhakhane, B. and S. Lubbe. 2005. Preliminaries into problems to access information - The digital divide and rural communities. South African Journal of Information Management 07(03).

Teffera, D. and P. G. Altbach. 2004. African higher education: Challenges for 21 st Century. Higher Education 47(1): 21-50.

UNDP see United Nations Development Programme. 
United Nations Development Programme. 2014. The impacts of social and economic inequality on economic development in South Africa. New York, USA: UNDP.

Vally, S. 2007. Higher education in South Africa: Market mill or public good? JHEA/RESA 5(1): 1728.

Wiese, M., C. H. van Heerden and Y. Jordaan. 2010. The role of demographics in students' selection of higher education institutions. Acta Commercii 10: 150-163.

Ziderman, A. 2009. Promoting access of disadvantaged groups through student loans prerequisites for success. Higher Education in Europe 34(2). 